\title{
REKAYASA PENYIMPANAN BENANGSARI DAN PENYERBUKAN PADA TANAMAN SALAK AMPELGADING
}

\section{ENGINEERING STORAGE OF STAMENS AND POLLINATION OF AMPELGADING SNAKEFRUIT}

\author{
Yuni Agung Nugroho' ${ }^{1)}$ dan Toto Suharjanto ${ }^{1)}$ \\ ${ }^{1)}$ Program Studi Agroteknologi, Fakultas Pertanian, Universitas Widyagama Malang, \\ Email: agung@widyagama.ac.id
}

\begin{abstract}
ABSTRAK
Setiap varietas tanaman salak mempunyai spesifikasi deskriptif meliputi warna kulit, tekstur buah, cita rasa daging dan aroma buah. Kematangan bunga betina dan bunga jantan tidak selalu bersamaan pada setiap kebun salak sehingga diperlukan cara agar dapat mempertahankan umur guna dari benangsari dan alat bantu penyerbukan yang dapat meningkatkan keberhasilan penyerbukan. Tujuan penelitian ini adalah untuk meningkatkan keberhasilan penyerbukan salak pondoh Ampelgading dengan rekayasa penyimpanan benangsari dan alat bantu penyerbukan. Penelitian menggunakan Rancangan Acak Kelompok, dengan perlakuan paduan antara rekayasa penyimpanan dengan jenis alat bantu penyerbukan. Setiap perlakuan diulang 3 kali. Sebagai kontrol adalah perlakuan dengan penyerbukan konvensional. Untuk analisa data kuantitatif dilakukan dengan menggunakan analisa ragam (uji F)) terhadap karakteristik buah salak pondoh (Salacca zalacca) hasil penyerbukan. Hasil penyimpanan 1 minggu pada semua perlakuan cara penyimpanan masih mampu mempertahankan kualitas benangsari tanaman salak pondoh. Namun pada penyimpanan umur 2 minggu menunjukkan bahwa pada suhu kamar dan eksikator sudah menunjukkan adanya jamur pada serbuksari yang disimpan, sedangkan pada penyimpanan di kulkas dan freezer masih bagus kondisi serbuksari. Penyimpanan satu minggu pada freezer kombinasi penyerbukan memakai kuas memberikan keberhasilan fruitset lebih banyak jika dibandingkan dengan kontrol.
\end{abstract}

Kata kunci: benangsari; penyerbukan; penyimpanan; rekayasa; salak pondoh

\section{ABSTRACT}

Each zalacca variety has descriptive specifications including skin color, fruit texture, meat taste and fruit aroma. Maturity female and male flowers are not always at the same time at each zalacca garden so it is needed a way to maintain the useful life of stamens and pollination aids that can increase the success of pollination. The purpose of this study is to increase the success of Ampelgading salak pollination with engineering of benangsari storage and pollination aids. The study used a Randomized Block Design with a combination of storage engineering with the type of pollination aids. Each treatment was repeated 3 times. As control is conventional pollination. For quantitative data analysis, the analysis of variance ( $F$ test) was carried out on the characteristics of salacca pondoh (Salacca zalacca) from pollination. One week storage results on all treatments of storage methods are still able to maintain the quality of stamen. However, at the age of 2 weeks of storage shows that at room temperature and the 
exitator has shown the presence of fungus in stored starch, while the storage in the refrigerator and freezer is still good condition. One week of storage at the freezer pollination combination using a brush gives more fruitset success when compared to controls.

Keywords: engineering; pollination; pondoh snakefruit;stamens;storage

\section{PENDAHULUAN}

Varietas memegang peranan penting dalam produktivitas dan cita rasa salak. Kultivar Salak Pondoh Hitam Kemerahan dan Manggala merupakan salak unggulan di Kecamatan Ampelgading Kabupaten Malang (Nugroho dan Suharjanto, 2013). Produksi salak pondoh di Ampelgading berkisar 5-10 $\mathrm{kg} /$ tanaman pertahun (Nugroho dan Suharjanto, 2012).

Salak Pondoh Merah Kehitaman merupakan salak pondoh unggul yang penanamannya menyebar luas di Kecamatan Ampelgading, karena tahan terhadap kerontokan dan rasa buahnya manis (Nugroho dan Suharjanto, 2012).

Konsumen menyukai salak berdaging tebal, citarasa manis sedikit ada rasa sepet, tahan lama disimpan dan sisik pada kulit buah tidak berduri (Sunaryono, 1988). Varietas salak yang mempunyai sifat seperti di atas sangat terbatas jumlahnya.

Tanaman salak pondoh berbunga berkali-kali, sementara tanaman jantan hanya berbunga sekali dalam setahun. Hal ini menyebabkan keterbatasan pembuahan pada tanaman salak pada setiap tahunnya. Sementara menurut Imam (1995) bahwa selama satu tahun, buah salak dapat dipanen sebanyak 4 kali, apabila tanaman jantannya dapat menyediakan serbuk sari untuk menyerbuki tanaman betina.

Penyerbukan salak dapat terjadi secara alami jika tanaman betina dan jantan berdekatan, akan tetapi jika letaknya berjauhan maka penyerbukan harus dibantu oleh manusia. Hal ini pun dapat dilakukan dengan baik bila tanaman jantan dan betina berbunga pada saat yang bersamaan (Tjahyadi, 1989). Penyerbukan sering terdapat kendala jika tanaman induk jantan 
berbunga lebih dahulu dari pada tanaman induk betina, sehingga dicari usaha untuk dapat menyimpan serbuk sari agar tetap dalam keadaan baik, sampai putik dari induk tanaman betina siap dibuahi. Dalam mengatasi hambatan tersebut, maka perlu usaha untuk menyimpan serbuk sari yang terlebih dahulu mekar agar tetap hidup tanpa kehilangan daya viabilitasnya (Swamy dan Krishnamurthy, 1980).

Penelitian bertujuan untuk meningkatkan keberhasilan penyerbukan salak Ampelgading melalui rekayasa penyimpanan benangsari dan penyerbukan.

\section{METODE}

\section{Area kajian}

Penelitian dilaksanakan MeiNopember 2016 di kebun salak pondoh Dusun Sidomarto Desa Sidorenggo Kecamatan Ampelgading Kabupaten Malang. Lokasi terletak pada ketinggian tempat $600 \mathrm{~m}$ dpl dengan suhu ratarata $10-28{ }^{\circ} \mathrm{C}$, kelembaban udara 86 $97 \%$ dan curah hujan rata-rata 1.562 $\mathrm{mm} /$ tahun.

Pengujian simpan serbuksari dilakukan di Laboratorium Biologi
Universitas Widyagama Malang dengan suhu rata-rata $18-30^{\circ} \mathrm{C}$ dan kelembaban udara 82-94\%. Dusun Sidokerto mempunyai suhu udara lebih rendah dengan kelembaban udara lebih tinggi jika dibandingkan dengan di Laboratorium Biologi Fakultas Pertanian Universitas Widyagama Malang.

\section{Bahan dan Metode}

Bahan penelitian terdiri dari induk betina tanaman salak yang digunakan dalam penelitian adalah induk betina Salak Pondoh Merah Kehitaman. Umur induk betina yaitu 7 tahun dan telah berproduksi. Bunga betina yang digunakan dalam proses penyerbukan yaitu bunga yang sudah mekar sempurna. Induk jantan yang digunakan berasal dari tanaman salak hasil persilangan salak pondoh merah kehitaman dengan keturunan suwaru.

Serbuksari yang dipakai dalam penelitian diambil dari bunga jantan sesuai perlakuan dengan cara mengetuk-ngetukkan tongkol bunga jantan pada tempat/wadah yang yang sudah disiapkan kemudian serbuksari yang terkumpul dimasukkan pada botol kemudian ditutup. 
Penelitian dilaksanakan dengan

menggunakan Rancangan Acak
Kelompok (RAK) dengan perlakuan, ditunjukkan pada tabel 1 .

Tabel 1. Perlakuan Rekayasa Penyimpanan dan Penyerbukan Salak

\begin{tabular}{|c|c|c|}
\hline $\begin{aligned} \text { FK 1= } & \text { Frezzer Kuas } \\
& \text { Penyimpanan } \\
& \text { Benangsari 1 } \\
& \text { minggu }\end{aligned}$ & $\begin{aligned} \text { FK } 2= & \text { Frezzer Kuas } \\
& \text { Penyimpanan } \\
& \text { Benangsari } 2 \text { minggu }\end{aligned}$ & $\begin{aligned} \text { FK } 3= & \text { Frezzer Kuas } \\
& \text { Penyimpanan } \\
& \begin{array}{l}\text { Benangsari } 3 \\
\text { minggu }\end{array}\end{aligned}$ \\
\hline $\begin{aligned} \text { FT 1 }= & \text { Frezzer Tiup } \\
& \text { Penyimpanan } \\
& \text { Benangsari 1 } \\
& \text { minggu }\end{aligned}$ & $\begin{aligned} \text { FT } 2= & \text { Frezzer Tiup } \\
& \begin{array}{c}\text { Penyimpanan } \\
\text { Benangsari } 2 \\
\text { minggu }\end{array}\end{aligned}$ & $\begin{aligned} \text { FT } 3= & \text { Frezzer Tiup } \\
& \text { Penyimpanan } \\
& \text { Benangsari } 2 \\
& \text { minggu }\end{aligned}$ \\
\hline $\begin{aligned} \text { KK 1= } & \text { Kulkas Kuas } \\
& \text { Penyimpanan } \\
& \text { Benangsari 1 } \\
& \text { minggu }\end{aligned}$ & $\begin{aligned} \text { KK 2= } & \text { Kulkas Kuas } \\
& \text { Penyimpanan } \\
& \text { Benangsari } 2 \text { minggu }\end{aligned}$ & $\begin{aligned} & \text { KK } 3= \text { Kulkas Kuas } \\
& \text { Penyimpanan } \\
& \text { Benangsari } 3 \\
& \text { minggu } \\
&\end{aligned}$ \\
\hline $\begin{array}{c}\text { KT } 1=\text { Kulkas Tiup } \\
\text { Penyimpanan } \\
\text { Benangsari 1 } \\
\text { minggu }\end{array}$ & $\begin{array}{c}\text { KT 2= KulkasTiup } \\
\text { Penyimpanan } \\
\text { Benangsari } 2 \\
\text { minggu }\end{array}$ & $\begin{aligned} \text { KT } 3= & \text { Kulkas Tiup } \\
& \text { Penyimpanan } \\
& \text { Benangsari } 2 \\
& \text { minggu }\end{aligned}$ \\
\hline $\begin{array}{c}\text { RK 1= Suhu Ruang } \\
\text { Kuas } \\
\text { Penyimpanan } \\
\text { Benangsari 1 } \\
\text { minggu }\end{array}$ & $\begin{aligned} \text { RT } 1= & \text { Suhu Ruang Tiup } \\
& \text { Penyimpanan } \\
& \text { Benangsari } 1 \text { minggu }\end{aligned}$ & $\begin{aligned} \text { EK } 1= & \text { Eksikator Kuas } \\
& \text { Penyimpanan } \\
& \text { Benangsari } 1 \\
& \text { minggu }\end{aligned}$ \\
\hline $\begin{array}{r}\text { ET 1= Eksikator Tiup } \\
\text { Penyimpanan } \\
\text { Benangsari 1 } \\
\text { minggu }\end{array}$ & Kontrol & \\
\hline
\end{tabular}

Keterangan :

1. Suhu freezer pada saat penyimpanan $-7^{\circ} \mathrm{C}$, sedangkan suhu kulkas $10^{\circ} \mathrm{C}$

2. Kontrol adalah perlakuan penyerbukan antara bunga betina salak pondoh merah kehitaman dengan bunga jantan yang sama, dengan cara menempelkan potongan bunga jantan pada bunga betina, dilakukan sesaat setelah pemotongan bunga jantan.

3. Perlakuan kontrol dilaksanakan pada hari $\mathrm{H}$, sedangkan perlakuan penyimpanan 1 minggu (frezer dan kulkas) dilakukan penyimpanan 1 minggu sebelum hari. Penyimpanan 2 minggu dilakukan 2 minggu sebelum hari $\mathrm{H}$ dan penyimpanan 3 minggu dilakukan 3 minggu sebelum hari $\mathrm{H}$, sehingga pelaksanaan penyerbukan utntuk semua perlakuan dilakukan bersamaan yaitu pada hari $\mathrm{H}$. 
Setiap perlakuan diulang 3 kali, pengulangan atau kelompok didasarkan pada kondisi kebun tanaman salak yang dipakai pada penelitian.

\section{Cara kerja}

\section{Persiapan Bunga Jantan}

Pengambilan bunga jantan dimulai dengan cara memangkas pelepah tanaman jantan agar lebih memudahkan dalam mengambil bunga yang sudah mekar. Bunga jantan yang digunakan adalah kuturunan suwaru dengan pondoh.

\section{Penetapan Induk Betina}

Induk betina yang digunakan dalam penelitian adalah induk betina Salak Pondoh Hitam Kemerahan yang berumur 7-9 tahun dan telah berproduksi.

\section{Proses Penyerbukan}

Penyerbukan dilakukan dengan cara memotong tongkol bunga jantan yang sudah mekar sepanjang $3 \mathrm{~cm}$ dengan menggunakan gunting. Selanjutnya menggunting ujung pembungkus bunga betina (tapas) agar mudah dibuka. Setelah ujung tapas dibuka, potongan bunga jantan diletakkan di atas bunga betina.

\section{Pemangkasan Tapas}

Pemotongan tapas dilakukan hingga pangkal tapas yang membungkus tangkai tongkol bunga. Waktu pemotongan tapas dilakukan 1 minggu setelah penyerbukan.

\section{Pengamatan}

Pengamatan dilakukan terhadap morfologi tanaman salak jantan, sedangkan pengamatan karakteristik buah muda dilakukan 3 bulan setelah penyerbukan yang meliputi: diameter buah muda, warna buah muda, dan bentuk buah muda, bertujuan untuk mengetahui peran masing-masing varietas induk jantan terhadap karakteristik buah yang dihasilkan.

\section{Analisis data}

Metode analisa yang dipakai dalam penelitian ini adalah penggabungan analisa kuantitatif dan kualitatif. Data primer yang berupa data morfologi buah salak dianalisa secara deskripsi komparatif dengan membanding profil buah salak pondoh pada masing-masing perlakuan. Data kuantitatif dari pengamatan jumlah buah pertandan dilakukan analisa ragam (uji F) pada taraf ketelitian $\alpha=5 \%$. Selanjutnya untuk mengetahui adanya beda di antara 
perlakuan di lakukan uji BNJ (Beda Nyata Jujur) dengan taraf ketelitian $95 \%$.

\section{HASIL DAN PEMBAHASAN}

\section{Pengujian Fisik Daya Simpan Benang Sari di Laboratorium}

Pengujian fisik daya simpan benang sari di Laboratorium.

Tabel 1. Hasil Penyimpanan Benangsari

\begin{tabular}{lcccc}
\hline \multirow{2}{*}{ Perlakuan } & \multicolumn{4}{c}{ Minggu ke- } \\
\cline { 2 - 5 } & 1 & 2 & \multicolumn{1}{c}{3} \\
\hline Suhu kamar & Baik & Baik & Berjamur & Berjamur \\
Eksikator & Baik & Baik & Berjamur & Berjamur \\
Kulkas & Baik & Baik & Baik & Baik \\
Freezer & Baik & Baik & Baik & Baik \\
\hline
\end{tabular}

\section{Pengujian Fisik Daya Simpan Benang} Sari di Lokasi Penelitian

Tabel 2. Hasil Penyimpanan Benangsari

\begin{tabular}{|c|c|c|c|}
\hline \multirow[t]{2}{*}{ Perlakuan } & \multicolumn{3}{|c|}{ Minggu ke- } \\
\hline & 1 & 2 & 3 \\
\hline Suhu kamar & Baik & $\begin{array}{l}\text { Berjamur } \\
\text { sebagian }\end{array}$ & Berjamur \\
\hline Eksikator & Baik & $\begin{array}{l}\text { Berjamur } \\
\text { sebagian }\end{array}$ & Berjamur \\
\hline Kulkas & Baik & Baik & $\begin{array}{l}\text { Berjamur } \\
\text { sebagian }\end{array}$ \\
\hline Freezer & Baik & Baik & Baik \\
\hline
\end{tabular}

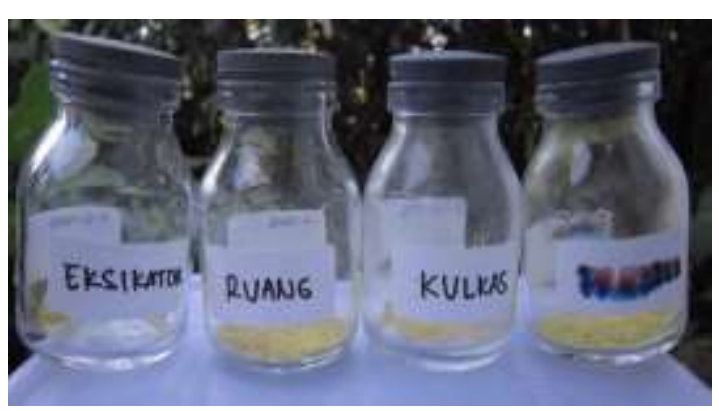

Gambar 1. Benangsari yang disimpan 1 (satu) minggu 

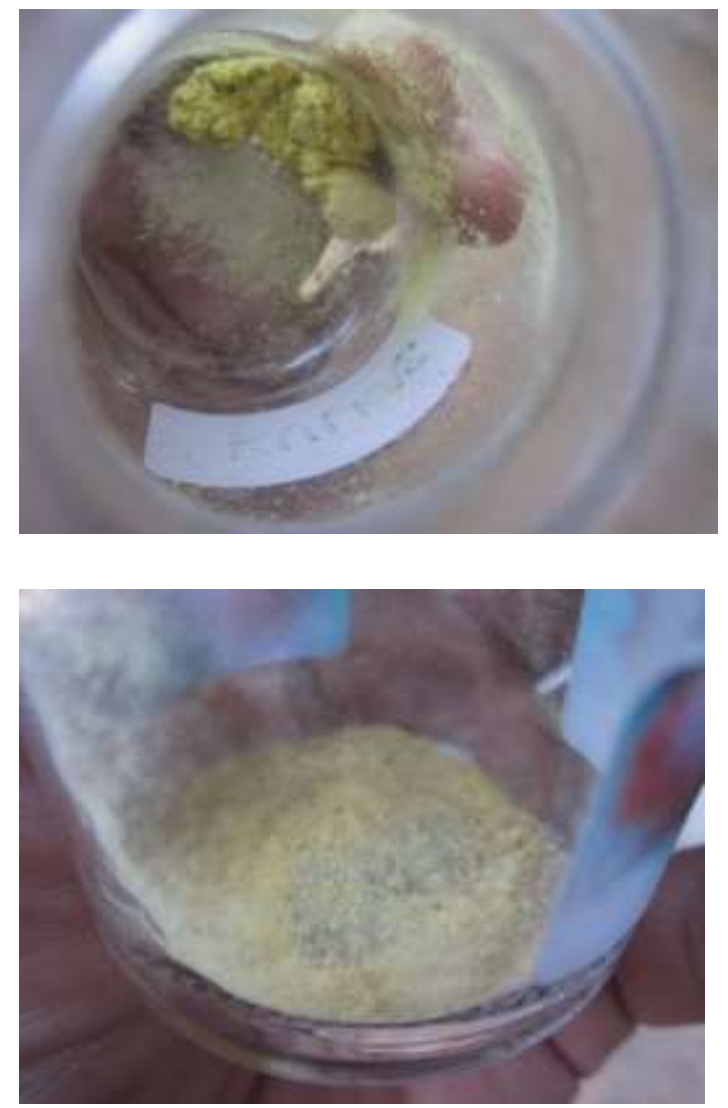

Gambar 3. Benangsari yang disimpan tiga minggu sudah mulai berjamur pada penyimpanan di kulkas, sedangkan penyimpanan pada freezer masih bagus

\section{Penyerbukan}

Benangsari yang disimpan satu minggu pada semua perlakuan penyimpanan diserbukkan pada bunga betina salak pondoh karena kondisi benangsari salak masih bagus tidak ada jamur.
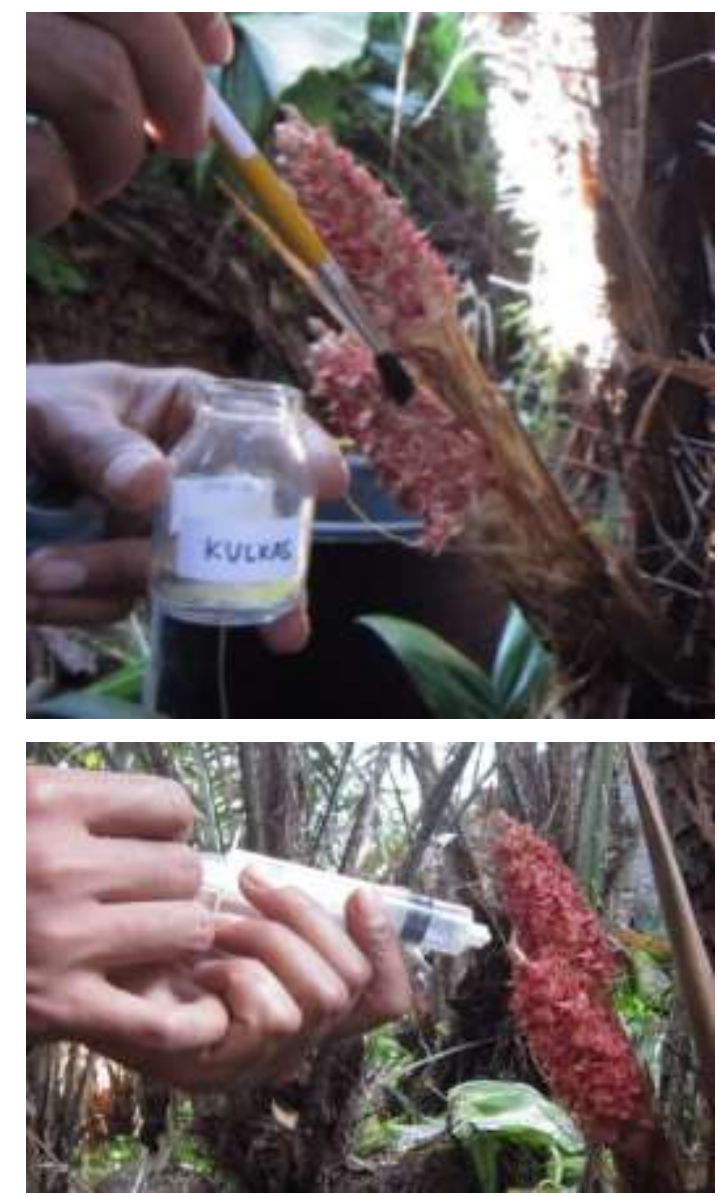

Gambar 4. Penyerbukan dengan alat bantu kuas dan spuit

Pada umur penyimpanan dua minggu, perlakuan penyimpanan pada kulkas dan freezer yang dilakukan penyerbukan karena kondisi benangsari yang disimpan masih bagus, sedangkan pada penyimpanan suhu kamar dan ekasikator sudah menunjukkan adanya jamur pada sebagian benangsari yang disimpan.

$$
\text { Pada umur penyimpanan tiga }
$$
minggu, perlakuan penyimpanan pada kulkas dan freezer yang dilakukan penyerbukan karena kondisi benangsari 
yang disimpan masih bagus, sedangkan pada penyimpanan suhu kamar dan ekasikator sudah menunjukkan adanya jamur pada sebagian benangsari yang disimpan.

\section{Hasil Penyerbukan}

Penyerbukan dengan serbuksari yang disimpan satu minggu pada semua jenis penyimpanan menunjukkan hasil yang baik. Hal ini ditunjukkan bahwa semua perlakuan penyerbukan berhasil menghasilkan buah muda.

Pada umur simpan serbuksari dua minggu yang disimpan pada kulkas dan frezzer masih menunjukkan kondisi yang bagus, sehingga dipakai sebagai bahan penyerbukan bunga betina. Hasil penyerbukan dengan bahan benangsari tersebut berhasil membentuk buah muda.

Tabel 2. Jumlah buah hasil penyerbukan

\begin{tabular}{lllllllllll}
\hline $\begin{array}{l}\text { Perlakuan } \\
\text { Penyimpanan }\end{array}$ & FK & FT & KK & KT & RK & RT & EK & ET & & Kontrol \\
\hline $\begin{array}{l}\text { Penyimpanan } \\
\quad \text { minggu }\end{array}$ & $53,0 \mathrm{f}$ & $33,0 \mathrm{~cd}$ & $40,0 \mathrm{de}$ & $33,0 \mathrm{~cd}$ & $15,0 \mathrm{a}$ & $12,0 \mathrm{a}$ & $12,0 \mathrm{a}$ & 11,0 & $\mathrm{a}$ & 38,0 cde \\
$\begin{array}{l}\text { Penyimpanan } \\
2 \text { minggu }\end{array}$ & $43,7 \mathrm{ef}$ & $37,0 \mathrm{cde}$ & $34,0 \mathrm{cde}$ & $31.3 \mathrm{~cd}$ & & & & & & \\
$\begin{array}{l}\text { Penyimpanan } \\
3 \text { minggu }\end{array}$ & $20,0 \mathrm{ab}$ & $32,7 \mathrm{~cd}$ & $31,3 \mathrm{~cd}$ & $28.3 \mathrm{bc}$ & & & & & & \\
\hline
\end{tabular}

Keterangan: Perlakuan yang diikuti dengan huruf yang sama menunjukkan tidak ada beda nyata pada uji Beda Nyata Jujur pada tingkat $\alpha=5 \%$.

Perlakuan-perlakuan yang bisa menyamai kontrol yaitu perlakuan yang biasa dilakukan petani dengan menggunakan pemotongan bunga jantan tanpa disimpan adalah perlakuan FK2, KK1, KK2, FT2, KT1, FT1, FT3, KT2, KK3, KT3. Hal tersebut menunjukkan bahwa penyimpanan pada kulkas dan Frezzer sampai dengan 3 minggu mempunyai kemampuan membentuk fruitset tidak berbeda secara nyata dengan yang biasa dilakukan petani.
Pemanfaatan alat bantu kuas dan spuit (alat suntik) mampu meningkatkan fruitset, yaitu pada perlakuan FK1 (frezzer kuas dengan serbuksari yang disimpan 1 minggu). Hasil analisa ragam selengkapnya ditunjukkan pada tabel 2.

$$
\text { Pemanfaatan alat bantu }
$$
penyerbukan menunjukkan bahwa alat bantu kuas dan tiup/spuit mampu menghasil penyerbukan yang baik, ditunjukkan dengan berhasilnya semua 
perlakuan penyerbukan yang menggunakan kedua alat bantu tersebut. Hasil penyerbukan dengan alat bantu tersebut tidak kalah bagus hasilnya jika dibandingkan dengan cara konvensional yang biasa dilakukan oleh petani di Ampelgading Kabupaten Malang.

Dari hasil analisa ragam sebagaimana yang ditunjukkan pada Tabel 2, menunjukkan bahwa penyimpanan serbuksari yang dipadukan dengan alat bantu penyerbukan baik dengan kuas maupun dengan alat tiup/spuit mampu menyamai hasil yang dilakukan secara konvensional. Bahkan pada penyimpanan dengan frezzer selama 1 minggu yang dipadukan dengan alat bantu kuas mampu mengungguli dari kontrol.

\section{Karakteristik Buah Salak}

Buah salak umur 16 minggu setelah penyerbukan menunjukkan pertumbuhan yang normal sebagaimana pertumbuhan pada perlakuan kontrol. Terjadi pengurangan jumlah buah karena adanya kerontokan yang disebabkan kelembaban udara yang tinggi di malam hari dan adanya hama bajing. Buah salak pondoh
Ampelgading ditunjukkan pada gambar $5,6,7$, dan 8 .

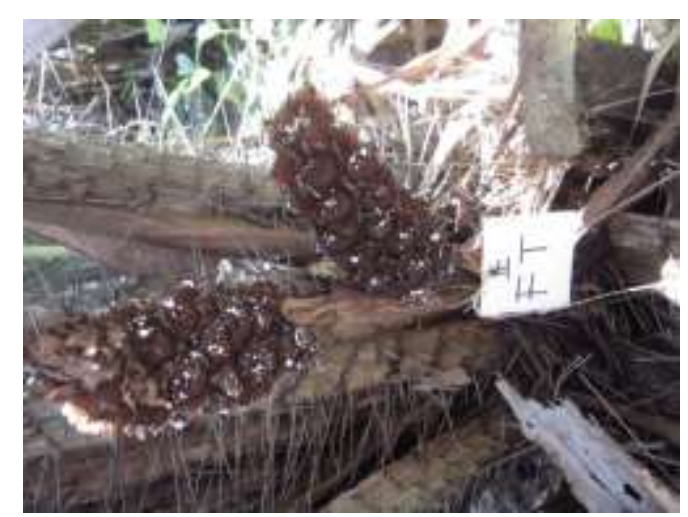

Gambar 5. Fruistset Salak dengan Perlakuan Freezer \& Tiup

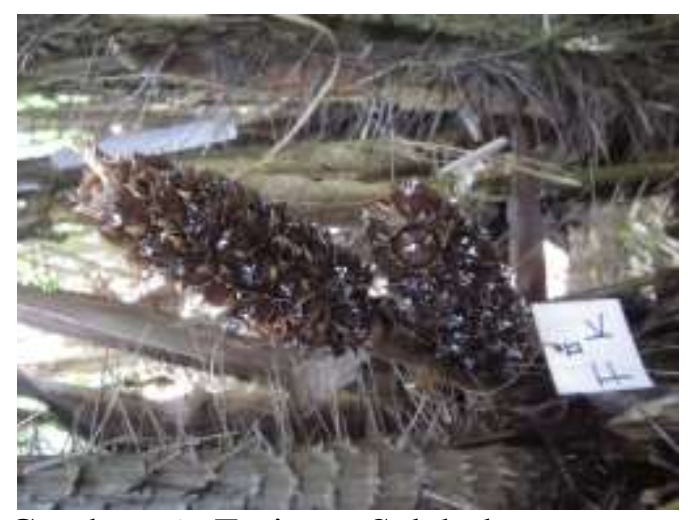

Gambar 6. Fruistset Salak dengan Perlakuan Freezer \& Kuas

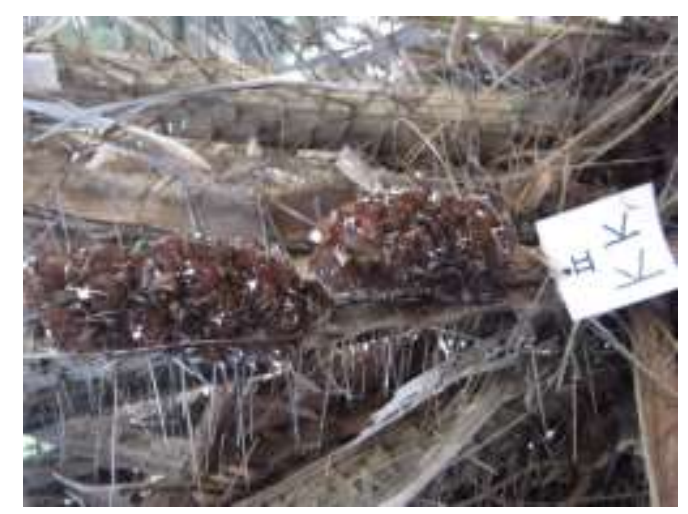

Gambar 7. Fruistset Salak dengan Perlakuan Kulkas \& Kuas 


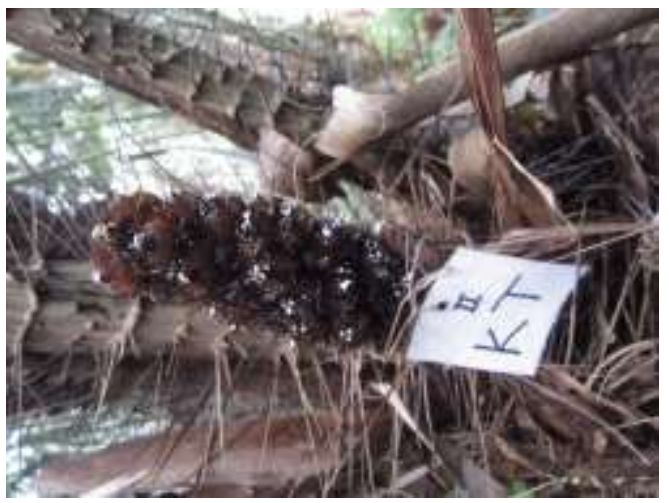

Gambar 8. Fruistset Salak dengan

Perlakuan Kulkas \& Tiup

Pengamatan fruitset dilakukan lagi setelah dilakukan penjarangan buah, pengurangan buah dengan penjarangan dicatat untuk mengoreksi susut jumlah buah. Jumlah buah setelah penjarangan berkurang sesuai dengan jumlah pengurangan buah muda pada saat penjarangan dilakukan. Penjarangan dilakukan untuk memberikan ruang bagi perkembangan buah secara optimal sehingga mencapai ukuran yang lebih besar daripada tandan buah yang tidak dilakukan penjarangan buah.

\section{KESIMPULAN DAN SARAN}

\section{Kesimpulan}

Terdapat perbedaan hasil uji simpan benangsari di laboratorium dengan di lokasi penelitian. Terjadi penurunan daya simpan benangsari yang diuji pada lokasi penelitian.
Alat bantu penyerbukan dengan kuas mampu memberikan keberhasilan penyerbukan lebih tinggi daripada menggunakan alat tiup/spuit maupun dengan metode konvensional (kontrol).

Penyimpanan pada kulkas dan frezzer mampu mempertahankan kualitas serbuksari sampai dengan umur dua minggu simpan. Penyimpanan selama satu minggu pada frezzer yang dipadu dengan penyerbukan memakai kuas memberikan hasil fruitset lebih tinggi dibandingkan dengan kontrol.

\section{Saran}

Penyimpanan dalam bentuk benangsari lebih tahan lama daripada dalam bentuk tongkol bunga jantan. Penyimpanan sebaiknya menggunakan botol yang tertutup rapat sehingga air tidak dapat masuk dan bercampur dengan benangsari, supaya tidak terjadi kerusakan benangsari karena jamur.

\section{UCAPAN TERIMA KASIH}

Kami sampaikan terimakasih kepada Direktur Riset dan Pengabdian Kepada Masyarakat, Ditjen Penguatan Riset dan Pengembangan, Kementerian Ristek dan Dikti yang telah 
memberikan kesempatan dan dana atas terlaksananya penelitian PHB dengan no kontrak 022/SP2H/P/K7/KM//2016.

\section{DAFTAR PUSTAKA}

Bowo, H dan Sukartiningrum. 2011. Biodiversity Of Salak Plant (Salacca Zalacca (Gaertner) Voss). ISNAR C2FS PROCEEDING. Surabaya June 27-28.

Fred W. S., R. Rutishauser and P. K. Endress. 2002. Morphology and development of the female flowers in Geonoma interrupta (Arecaceae). American Journal of Botany. 89:220-229.

Gorinstein, S., R. Haruenkit, S. Poovarodom, Y.S. Park, S. Vearasilp, M. Suhaj, K.S. Ham, B.G. Heo, J.Y. Cho, and H.G. Jang. 2009. The Comparative Characteristics of Snake and Kiwi Fruit. Food and Chemical Toxicology. 49: 1884-1891.

Hambali, G. 1994. Spesies dan Varietas Salak. Jakarta: Trubus.

Heywood, V.H. 1967. Plant Taxonomy. St. Martin's Press. New York.

Nugroho, Y.A. dan T. Suharjanto. 2012. Keragaan Sifat morfologi Salak Pondoh (Salacca zalacca) di Kecamatan Ampelgading Kabupaten Malang. Agrika. 6(2): 161-173.

Nugroho, Y.A. dan T. Suharjanto. 2013. Pencitraan Salak Pondoh Unggul
Baru dan Karakteristik Hubungan Morfologi Tanaman Salak Pondoh (Salaca zalacca) di Kecamatan Ampelgading Kabupaten Malang. Laporan Penelitian PDP. DP2M Dikti.

Nugroho, Y.A. dan T. Suharjanto. 2015. Rekayasa Teknologi Penyerbukan Pada Salak Pondoh (Salaca zalacca) untuk Mewujudkan Salak Ampelgading Berkualitas Prima. Laporan Penelitian PHB Tahun I (Pertama).

Shivanna, K. R., H.F. Linkens, and M. Cresti. 1991. Pollen viability and pollen vigor. Theor. Appl. Genet. 81: $38-42$.

Sofro, A.S.M. 1994. Keanekaragaman Genetik. Andi Offset. Yogyakarta.

Surachmat, K. 1989. Penggandaan Bibit Buah-Buahan". Dalam: Makalah pada Latihan Produksi Benih dan Teknologi Benih Puspalitbang Hortikultura. $15 \quad$ Mei 1989 di Segunung. 